\title{
AT ETERNITY'S GATE: TEMPORAL LOBE EPILEPSY AND THE GENIUS OF VINCENT VAN GOGH
}

\author{
Mousa Taghipour, Nima Derakhshan \& Arash Saffarian \\ Neurosurgery Department, Shiraz University of Medical Sciences, Shiraz, Iran \\ $* * * * *$
}

\section{INTRODUCTION}

We came across the very interesting article by Yasmeen Cooper and Mark Agius (2018) questioning the fact whether neuropsychiatric symptoms of Van Gogh can be explained by schizoaffective disorder.

Several articles have investigated the mental illness of Van Gogh and it's still a matter of debate. Schizoaffective disorder, Meniere's disease, tertiary syphilis, acute intermittent porphyria, lead and terpenoid poisoning, brain tumors, temporal lobe epilepsy (TLE) and Vascular dementia have been proposed as his underlying condition.

However, most authorities believe that his symptoms cannot be explained with a single condition.

Epilepsy is a common condition affecting more than 0.5 to $1 \%$ of world population and it is among the oldest recognized diseases, with written records dating back to 4000 BC. Several famous people in the fields of art, science, politics and religion are known to sustain epileptic disorders. Here in, we tend to describe temporal lobe epilepsy (TLE), as a condition that may lead to ingenuity in humankind, with several historical instances and we particularly focus on the famous Dutch painter Vincent van Gogh.

\section{THE THEORY OF INGENUITY IN TLE PATIENTS}

The underlying mechanism which leads to special capabilities in several instances of TLE patients lies beneath the loss of inhibition imposed by inhibitory basket cell interneurons. The neural connections in mesial temporal structures are summarized in Figure 1.

Following a hypoxic insult in early stages of life, inhibitory GABA ( $\gamma$-aminobutyric acid)-ergic basket cell interneurons which are abundant in Cornu Ammonis 1 or CA1 (the most vulnerable region of brain to hypoxic damage) are lost. (Aitken \& Schiff 1986) A phenomenon called kindling phenomenon (Sutula \& Kotloski 2017) happens with loss of inhibitory control over this circuit, which fires several neurons in this area and is manifested with epileptic seizures.

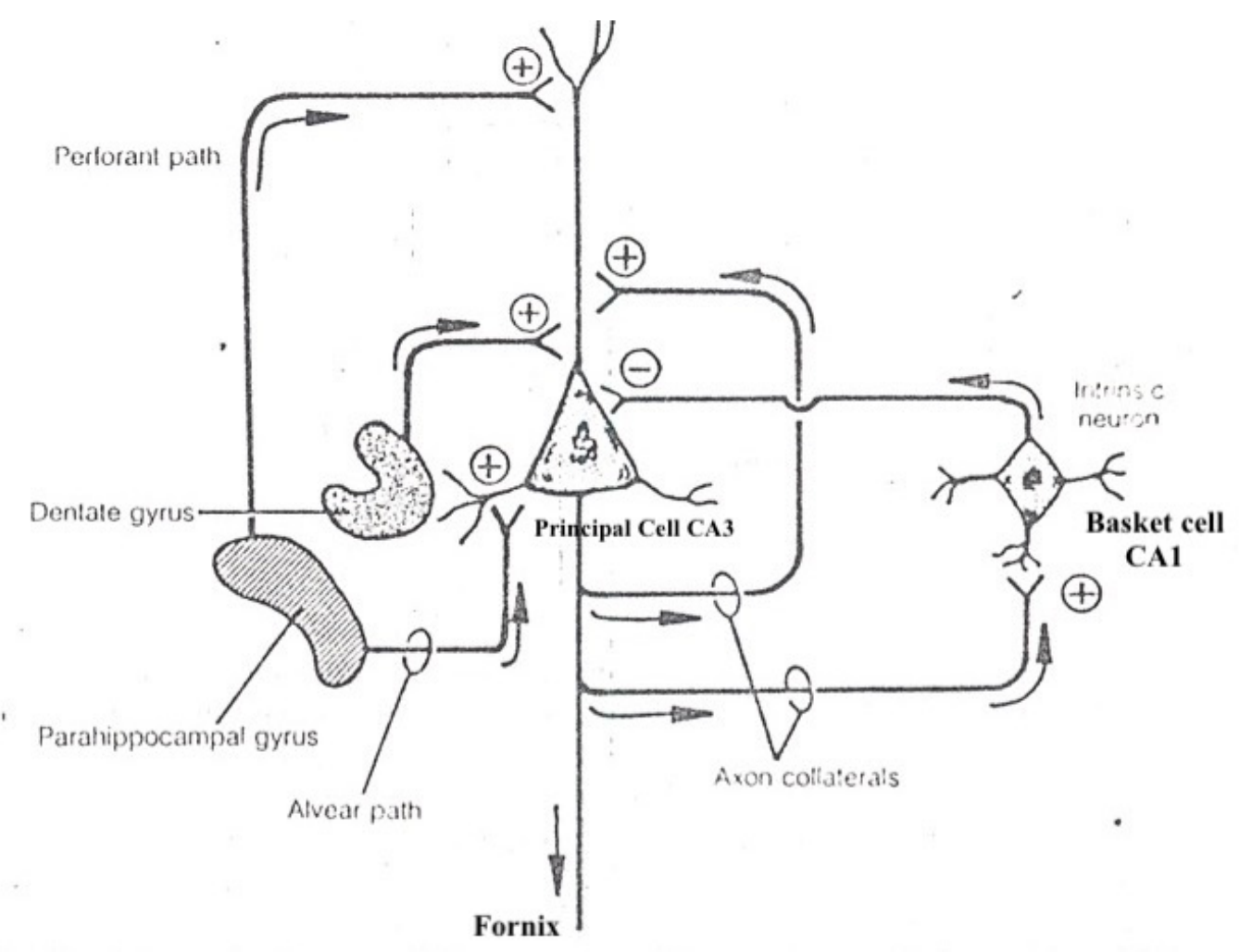

Figure 1. Mesial temporal structures 
Table 1. Different manifestations of TLE

\begin{tabular}{|c|c|c|}
\hline $\begin{array}{l}\text { Name of Famous People } \\
\text { Sustaining TLE }\end{array}$ & $\begin{array}{l}\text { Specific TLE } \\
\text { Manifestations }\end{array}$ & Structures and Circuits Involved \\
\hline Joan of Arch & $\begin{array}{l}\text { Auditory hallucinations; } \\
\text { Pleasure and Revelation }\end{array}$ & $\begin{array}{l}\text { Long association fibers to association auditory cortex; } \\
\text { Nauta (Pleasure) Circuit; Right limbic mesial } \\
\text { temporal structures (Taghipour \& Derakhshan 2018) }\end{array}$ \\
\hline Dostoevsky & Pleasure & Nauta (Pleasure) Circuit \\
\hline $\begin{array}{l}\text { Vincent van Gogh } \\
\text { (Richardson et al. 2017) }\end{array}$ & Rage and grief & $\begin{array}{l}\text { Amygdala- Emotion Circuit (Taghipour \& } \\
\text { Ghaffarpasand 2018) }\end{array}$ \\
\hline Minakata Kumagusu & Déjà vu & Long association fibers to association visual cortex \\
\hline
\end{tabular}

(TLE confirmed with Right hippocam-

pal atrophy in his post-mortem MRI)

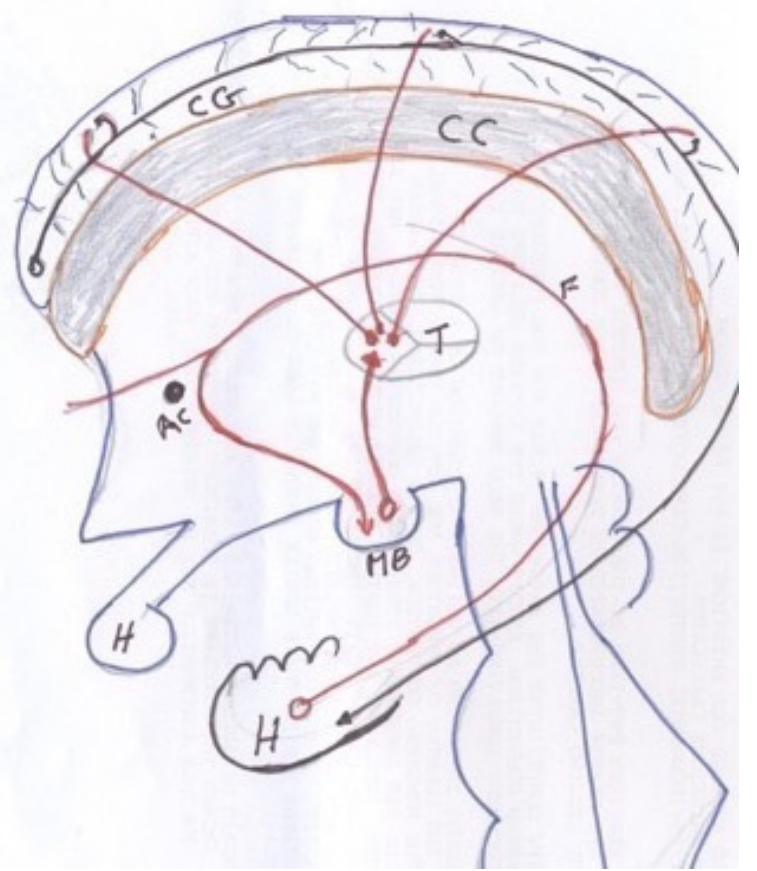

Figure 2. Papez circuit for memory

Considering the hippocampus as the entering gate of data to human brain, this loss of inhibition, may also lead to faster and better cognitive abilities. The inputs to the hippocampus (which is the primary station in Papez circuit for memory, Figure 2), will have a facilitated relay to the cerebral cortex, with loss of this inhibitory control in TLE sufferers which justifies their ingenuity.

\section{DIFFERENT MANIFESTATIONS OF TLE IN GENIUS PEOPLE}

Several types of focal seizures are reported in genius people with TLE, which shows the different structures and circuits involved. For example, Joan of Arc had instances of hallucination and revelation, Minakata Kumagusu suffered attacks of Déjà vu, Dostoevsky experienced pleasure and joy and Vincent van Gogh manifested with moments of rage during his seizures. (summarized in Table 1)
Showing rage is best justified with activation of amygdala, an almond-shaped cluster of nuclei in mesial part of each temporal lobe which has a key role in fight and flight circuit of brain.

\section{RAGE AS A MANIFESTATION OF SHAME}

Several documents are available showing Van Gogh's spells of rage, such as self-mutilation and suicide. The presentation of rage spells proves that a defective amygdala signaling was present in case of Van Gogh. However, most instances of his rage spells were rage at himself. From a sociologic perspective Van Gogh has been described as a shameful person. (Meissner 1996) Karl Marx describes shame as a social emotion which is a kind of anger which is turned inward. (Weyher 2012) This concept will justify van Gogh's spells of self-rage as shame.

\section{THE DOUBLE-EDGED SWORD OF TLE}

Even though TLE might have made a creative and genius artist out of Van Gogh, (due to facilitation in memory and emotion circuitry of his brain), same pathology led to the spells of self-rage and anger (in accordance with the famous story of mutilating his left ear and giving him to a prostitute) which is known as van Gogh syndrome. This syndrome manifests itself as self-mutilation of organs such as genitals, ear and limbs in particular. He finally committed suicide by shooting himself as one of the self-rage attacks mentioned in the previous section as an issue of shame.

His last words show the grief and rage in his recent moments of life: "Grieving is eternal."

Acknowledgements: None.

\section{Conflict of interest: None to declare.}

\section{Contribution of individual authors:}

Mousa Taghipour proposed the design of the study. Nima Derakhshan wrote the manuscript.

Arash Saffarian helped with literature searches. 


\section{References}

1. Aitken $P G \&$ Schiff SJ: Selective neuronal vulnerability to hypoxia in vitro. Neurosci Lett 1986; 67:92-6

2. Cooper $Y \&$ Agius M: Does Schizoaffective Disorder explain the mental illnesses of Robert Schumann and Vincent Van Gogh? Psychiatr Danub 2018; 30(suppl 7):S559-562

3. Meissner WW: The shame dynamic in Vincent van Gogh. Annual of Psychoanalysis 1996; 24:205-225

4. Richardson BA, Rusyniak AM, Rusyniak Jr WG, Rodning $C B$ : Neuroanatomical interpretation of the painting starry night by Vincent van Gogh. Neurosurgery 2017; 81:389-396
5. Sutula TP, Kotloski RJ. Kindling: A model and phenomenon of epilepsy. In Models of seizures and epilepsy 2017; 813-825. (Academic Press)

6. Taghipour M, Derakhshan N: Joy of learning: Mammilotegmental tract connecting 2 circuits of memory and pleasure in brain. World Neurosurg 2018; 118:387-388

7. Taghipour M, Ghaffarpasand F: Selective amygdalohippocampectomy for mesial temporal sclerosis: Special considerations in geniuses. World Neurosurg 2018; 111:429-430

8. Weyher LF: Re-reading sociology via the emotions: Karl marx's theory of human nature and estrangement. Sociological Perspectives 2012; 55:341-363

\section{Correspondence:}

Assistant Professor Nima Derakhshan, MD

Shiraz University of Medical Sciences, Neurosurgery Office, Namazi Hospital

Namazi Square, Shiraz, 71937-11351, Iran

E-mail: nima_med83@yahoo.com 